Full length article

\title{
Voluntary wheel running protects against the increase in ethanol consumption induced by social stress in mice
}

\author{
M.D. Reguilón, C. Ferrer-Pérez, R. Ballestín, J. Miñarro, M. Rodríguez-Arias* \\ Department of Psychobiology, Facultad De Psicología, Universitat De Valencia, Avda. Blasco Ibáñez, 21, 46010 Valencia, Spain
}

\section{A R T I C L E I N F O}

\section{Keywords:}

Social stress

Ethanol

Neuroinflammation

Chemokines

Physical exercise

Self-administration

\begin{abstract}
A B S T R A C T
Previous studies have shown that exposure to social defeat (SD), a model of social stress, produces a long-term increase in the consumption of ethanol, most likely through an increase in the neuroinflammation response. The aim of the present study was to evaluate whether exposure to physical activity in the form of voluntary wheel running (VWR) could block the increase in ethanol consumption and the neuroinflammatory response induced by social stress. Mice were exposed to either 4 sessions of repeated social defeat (RSD) or a non-stressful experience. During the whole procedure, half of the mice were exposed to controlled physical activity, being allowed $1 \mathrm{~h}$ access to a low-profile running wheel three times a week. Three weeks after the last RSD, animals started the oral self-administration (SA) of ethanol $(6 \% \mathrm{EtOH})$ procedure. Biological samples were taken $4 \mathrm{~h}$ after the first and the fourth RSD, 3 weeks after the last RSD, and after the SA procedure. Brain tissue (striatum) was used to determine protein levels of the chemokines fractalkine (CX3CL1) and SDF-1 (CXCL12). RSD induced an increase in ethanol consumption and caused greater motivation to obtain ethanol. The striatal levels of CX3CL1 and CXCL12 were also increased after the last RSD. VWR was able to reverse the increase in ethanol intake induced by social stress and the neuroinflammatory response. In conclusion, our results suggest that VWR could be a promising tool to prevent and reduce the detrimental effects induced by social stress.
\end{abstract}

\section{Introduction}

Social stress is deeply implicated in the neural and behavioral alterations that contribute to the development of mental health disturbances and drug addiction (Beutel et al., 2018). Stressful experiences modify the reward system and are involved in the transition from drug abuse to addiction, causing an increase of intake and drug-seeking behaviors (Koob and Schulkin, 2019; Miczek et al., 2008; MontagudRomero et al., 2016, 2018; Ruisoto and Contador, 2019). Social defeat (SD) is one of the most commonly used animal models to study the effects of stressful experiences. In this model, the experimental subject is repeatedly confronted with an aggressive opponent mouse (Miczek et al., 2004). SD induce a short-term increase in consumption of ethanol (EtOH) using oral self-administration (SA) with a higher motivation to get the drug (Van Erp and Miczek, 2001; Norman et al., 2015). In a previous study, we found that the effects of repeated social defeat (RSD) can be long-lasting, since mice exposed to RSD during adolescence showed higher ethanol consumption rates and a greater motivation to get the drug during adulthood (Rodríguez-Arias et al., 2016). Even after 6 months since the last stress exposure, defeated animals showed an enhanced motivation for ethanol intake (Riga et al., 2014). In addition, many studies support that social stress is one of the most important factors that influence the increase and escalation in ethanol consumption. Using voluntary ethanol intake, in the two bottle choice (TBC) task, SD produces an escalation in the consumption of alcohol after 10 days since the last exposure of stress (Norman et al., 2015; Hwa et al., 2016; Karlsson et al., 2017; Newman et al., 2018), although this effect is not observed immediately after being exposed to stress (Lopez et al., 2016). This increase in ethanol consumption induced by social stress could be due to stress-induced neuroadaptations, which ultimately produce changes in the hypothalamic, extrahypothalamic and mesocorticolimbic circuits, which are related to stress and reward (Holly et al., 2016; Hwa et al., 2016; Laine et al., 2017; Newman et al., 2018).

Nowadays, physical activity has emerged as a modulator of higher mental functions. Voluntary wheel running (VWR) in rodents produces enhanced learning, neurogenesis, angiogenesis, increases in

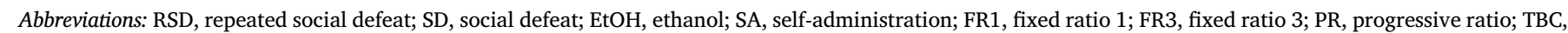

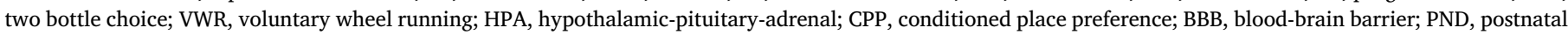
day

* Corresponding author.

E-mail address: marta.rodriguez@uv.es (M. Rodríguez-Arias). 
neurotrophic factors and changes in several signaling molecules, as well as a reduction in behaviors associated with stress (Salam et al., 2009; Mul, 2018). VWR exercise after SD reduced social avoidance and anhedonia in rodents (Mul et al., 2018; Watanasriyakul et al., 2018; Zhang et al., 2019). It is known that physical exercise regulates some components of the hypothalamic-pituitary-adrenal axis (HPA), generating an adaptive response to stress (Pietrelli et al., 2018). Moreover, rats exposed to long-term access to VWR showed alterations in gene transcription factors involved in reward and dopaminergic neurotransmission in the mesolimbic reward pathway, developing conditioned place preference (CPP) to the compartment associated with physical exercise (Greenwood et al., 2011). Therefore, mice consumed significantly less ethanol in the unlimited access TBC model when they had access to the wheel (Ehringer et al., 2009; Darlington et al., 2014, 2016).

A number of recent reports have studied the relationship between stress, addiction and the immune system. Both exposure to stress and ethanol consumption activate the immune system and induce neuroinflammation (Calcia et al., 2016; Finnell and Wood, 2016; Rodríguez-Arias et al., 2017; Ferrer-Pérez et al., 2018; Montagud-Romero et al., 2018). Moreover, deregulation in chemokine signaling and neuroinflammation have been proposed to contribute to cognitive dysfunction and mental illness (Keogh and Parker, 2011; Wohleb et al., 2013; Pascual et al., 2015). SD-induced neuroinflammation has been clearly demonstrated, characterized by an activation of microglia (Stankiewicz et al., 2015), an increase of pro-inflammatory cytokines (Wohleb et al., 2011, 2012, 2014; Ferrer-Pérez et al., 2018), or the cross of peripheral immune cells to the CNS due to higher blood-brain barrier (BBB) permeability (Rodríguez-Arias et al., 2017).

There are no current studies evaluating the role of VWR in ameliorating the increase in $\mathrm{EtOH}$ consumption induced by SD. In mice and humans, several studies suggest that excessive or forced physical exercise produces brain injury and neuroinflammation (Svensson et al., 2016; Paolucci et al., 2018). However, physical exercise also upregulates tight-junction associated proteins of the $\mathrm{BBB}$ and protects the brain from injury, reducing the activation of microglia and cytokine levels in the hippocampus in mice (Park et al., 2016; Spielman et al., 2017) and humans (Paolucci et al., 2018). Therefore, it is necessary to evaluate if the neuroinflammatory process induced by RSD mediates the increase in EtOH consumption and if VWR could modify it. The aim of the present study was, firstly, to confirm that RSD induces a longlasting increase in EtOH consumption using oral EtOH SA when experienced during adulthood; secondly, to evaluate if VWR could decrease these RSD effects on EtOH; and finally, to evaluate the neuroinflammatory response induced by RSD and $\mathrm{EtOH}$, measuring the striatal levels of two chemokines fractalkine (CX3CL1) and SDF-1 (CXCL12). Chemokines are a family of small cytokines with chemo-attraction characteristics. Social stress is known to intervene in the signaling of chemokines on microglial morpho-functional activity (Wohleb et al., 2013; Sawicki et al., 2015; Milior et al., 2016) and, in addition, the striatal levels CX3CL1 increase after EtOH intake (Pascual et al., 2015).

\section{Material and methods}

\subsection{Subjects}

A total of 115 male OF1 mice (Charles River, France) were delivered to our laboratory at postnatal day (PND) 21 (4 animals were discarded during the training phase of SA). All mice (except those used as aggressive opponents) were housed in groups of five in plastic cages (25 $\times 25 \times 14.5 \mathrm{~cm}$ ). Mice used as aggressive opponents were individually housed in plastic cages $(23 \times 13.5 \times 13 \mathrm{~cm})$ for a month before the experiments to induce heightened aggression (Rodríguez-Arias et al., 1998) ( $n=15$ adult mice). All mice were housed under the following conditions: constant temperature, a reversed light schedule (lights off at 08:00 and on at 20:00), and food and water were freely available ad libitum, except during the behavioral tests. All procedures were conducted in compliance with the guidelines of the European Council Directive 2010/63/UE regulating animal research and were approved by the local ethics committees (University of Valencia).

\subsection{Drugs}

For the oral SA procedure, absolute ethanol (Merck, Madrid, Spain) was diluted in water using a $\mathrm{w} / \mathrm{v}$ percentage, i.e. a $6 \%(\mathrm{w} / \mathrm{v})$ ethanol solution equivalent to a $7.6 \%(\mathrm{v} / \mathrm{v})$ ethanol solution. Saccharin sodium salt (Sigma, Madrid, Spain) was dissolved in water.

\subsection{Experimental design}

A first set of mice were employed to corroborate that social stress produces neuroinflammation. Animals were sacrificed $3 \mathrm{~h}$ after the first exploration (Control group), the first and the fourth RSD and 3 weeks after the last exposure to RSD.

Our main objective was to confirm the increase of voluntary ethanol consumption in defeated animals and to evaluate the action of physical exercise on this social stress effect. Animals were exposed to RSD (RSD and RSD + Wheel groups) or exploration condition (EXP and EXP + Wheel). Furthermore, the EXP + Wheel and RSD + Wheel groups were exposed, individually and in a different cage from the usual mice home cage, to wheel activity three days a week from PND 40 until the end of the SA procedure. This groups trained in the wheel for $1 \mathrm{~h}$ before each RSD or exploration condition. Three weeks after the last exposure to $\mathrm{RSD}$, the animals started the EtOH SA protocol for approximately 28 days. Brain samples were also obtained $24 \mathrm{~h}$ after the SA procedure.

\subsection{Repeated social defeat}

Animals in the stress/defeated groups were exposed to 4 episodes of RSD lasting 25 min each on PND 47, 50, 53 and 56. Each episode consisted of three phases, which began by placing the experimental animal or intruder in the home cage of the aggressive opponent for 10 min. During this initial phase, the intruder was protected from attack by a wire mesh wall that permitted social interaction and species-typical threats from the aggressive opponent (Covington and Miczek, 2001). In the second phase, the wire mesh was removed from the cage and a 5min period of confrontation began. The second phase of each RSD protocol was video-recorded and ethologically analyzed. Threat and attack behaviors were scored in aggressive opponent mice and avoidance/flee and defensive/submissive behaviors were evaluated in intruder mice. In the third phase, the wire mesh was put back for a further $10 \mathrm{~min}$ to allow social threats from the aggressive opponent. The nonstressed exploration groups underwent the same protocol, but without the presence of an aggressive opponent mouse in the cage. Following this last phase, animals were kept in the vivarium for three weeks, after which the behavioral tests began (see Fig. 1).

In the corresponding groups, animals ran on the wheels immediately before each RSD or exploration (control group).

\subsection{Apparatus and procedures}

\subsubsection{Oral ethanol self-administration}

This procedure is based on the one employed by Navarrete et al. (2014). Oral ethanol SA was carried out in 7 modular operant chambers (MED Associated Inc., Georgia, VT, USA). Packing software (Cibertec, SA, Spain) controlled stimuli and fluid delivery and recorded operant responses. The chambers were equipped with a chamber light, two nose-poke holes, one receptacle to deliver a liquid solution, one syringe pump, one stimulus light, and one buzzer and were placed inside noise isolation boxes. Active nose-poke delivered $36 \mu \mathrm{L}$ of fluid combined with a $0.5 \mathrm{~s}$ stimulus light and a $0.5 \mathrm{~s}$ buzzer beep, which was followed by a 6-s time-out period. The inactive nose-poke did not produce any 


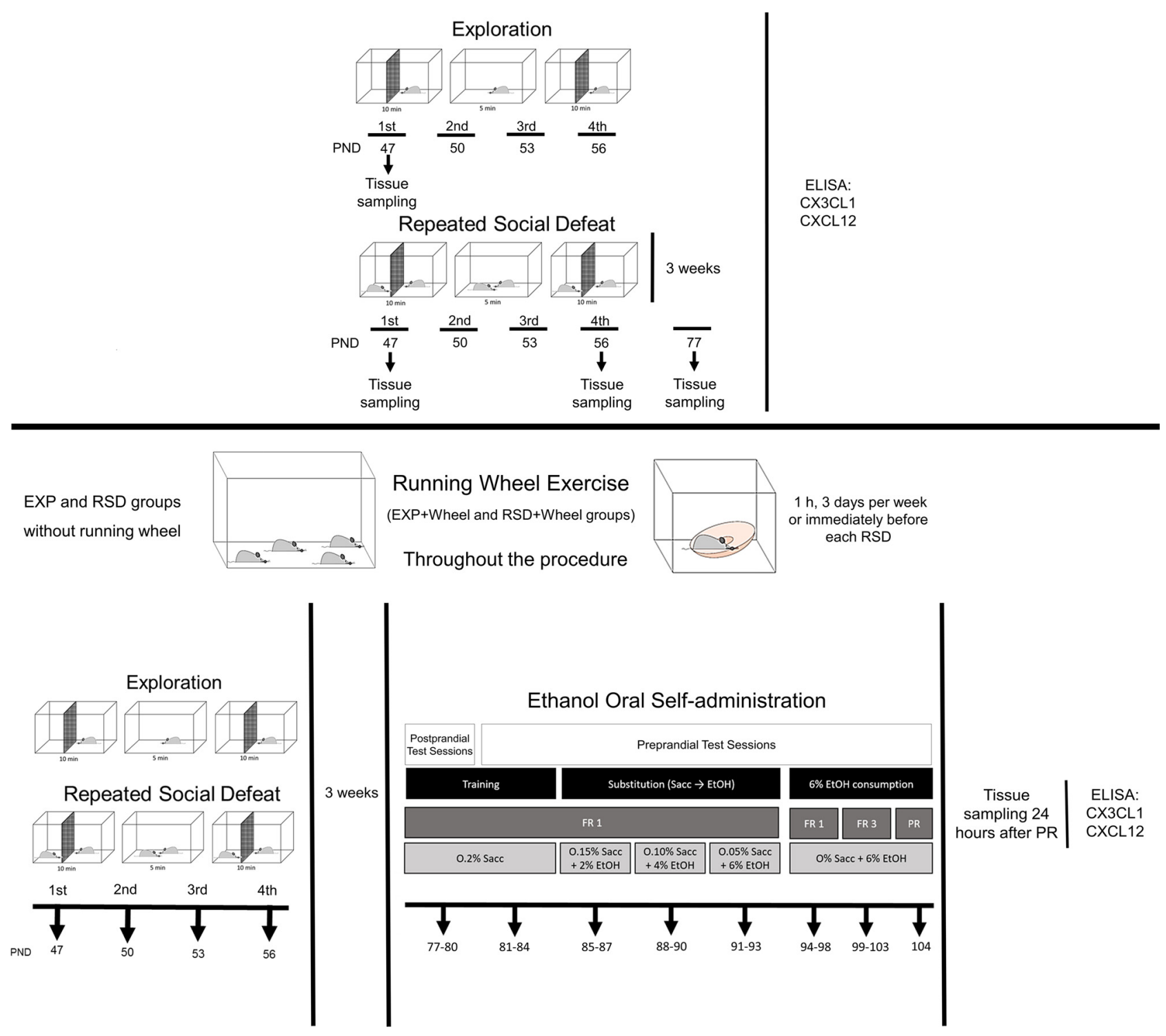

Fig. 1. Experimental design.

consequence.

To evaluate the consequences of RSD on the acquisition of oral EtOH SA, animals underwent an experiment carried out in three phases: training, saccharin fading and 6\% EtOH consumption.

Training phase ( 8 days): Two days before the initiation of the experiment, access to the standard diet was restricted to $1 \mathrm{~h}$ per day. Before the first training session, water was withheld for $24 \mathrm{~h}$, and food was provided $1 \mathrm{~h}$ prior to the $1 \mathrm{~h}$ session to increase the animals' motivation. During the subsequent 3 days, water was provided ad libitum, except during the 1-h period of food access before beginning each session, in which the water bottle was removed from the cages (postprandial). For the following four days, and for the remainder of the experiment, food access was provided for 1-h after the end of each daily session and water was available ad libitum to avoid EtOH consumption due to thirst (preprandial). The food restriction schedule produced in the mice weight loss of around $15 \%$ of their free-feeding weight (Navarrete et al., 2012). Mice were trained to respond to the active nose-poke to receive $36 \mu \mathrm{L}$ of $0.2 \%(\mathrm{w} / \mathrm{v})$ saccharin reinforcement.

Saccharin fading (9 days): The saccharin concentration was gradually decreased as the EtOH concentration was gradually increased (Roberts et al., 2001; Samson, 1986). Each solution combination was set up to three consecutive sessions per combination $(0.15 \%$ Sac $-2 \%$
EtOH; 0.10\% Sac - 4\% EtOH; 0.05\% Sac -6\% EtOH).

$6 \%$ ethanol consumption (11 days): The aim of the last phase was to evaluate the number of responses on the active nose-poke, the $6 \% \mathrm{EtOH}$ $(\mathrm{w} / \mathrm{v})$ intake and the motivation to drink. After each session, the alcohol that remains in the receptacle was collected and measured with a micropipette. To achieve this goal, during the last phase, the number of active responses and $\mathrm{EtOH}$ consumption $(\mu \mathrm{L})$ were measured under a fixed ratio 1 (FR1) for 5 daily consecutive sessions, a fixed ratio 3 (FR3) (mice had to respond three times on the active nose-poke to achieve one reinforcement) for 5 consecutive daily sessions, and finally, on the day after FR3, a progressive ratio (PR) session was completed to establish the breaking point for each animal (the maximum number of nosepokes each animal is able to perform to earn one reinforcement). The response requirement to achieve reinforcements escalated according to the following series: 1-2-3-5-12-18-27-40-60-90-135-200-300-450-6751000. To evaluate motivation toward EtOH consumption, the breaking point was calculated for each animal as the maximum number of consecutive responses it performed to achieve one reinforcement, according to the aforementioned scale (for example, if an animal activates the nose-poke a total of 108 times, this meant that it was able to respond a maximum of 40 times consecutively for one reinforcement. Therefore, the breaking point value for this animal would be 40). All 
the sessions lasted for $1 \mathrm{~h}$, except the PR session, which lasted for $2 \mathrm{~h}$.

\subsubsection{Low-profile running wheel}

The type of wheel used was the low-profile running wheel (Med Associates Inc.), which rotates on a central axis in a horizontal plane, allowing physical activity to be carried out through natural exercise as in spontaneous locomotion. These wheels have an ideal size $(10.25 \times$ $15.5 \times 13.7)$ to be introduced into the home cages of rodents and are linked to a monitoring system (Hub) that runs on batteries and can register the activity through a set of programs (Wheel Manager Software). All mice were housed in groups of five in plastic cages throughout the experiment. However, mice in the exercise condition (EXP + Wheel and RSD + Wheel) were individually placed in a plastic cage different to their home cage with one low-profile running wheel. In our laboratory, we have eight low-profile running wheels. All animals in the exercise condition were distributed in batches of eight to run on the wheel for $1 \mathrm{~h}$, three times a week (Monday, Wednesday, and Friday) or immediately before exposure to RSD.

\subsection{Tissue sampling}

Striatum samples were taken $3 \mathrm{~h}$ after the first and the fourth RSD. Likewise, another sample was taken three weeks later and a final sample was obtained after the end of the SA procedure.

To obtain tissue samples, mice were sacrificed by cervical dislocation and then decapitated. Brains were rapidly removed, the striatum dissected following the procedure described by Heffner et al. (1980) and kept in dry ice until storage at $-80^{\circ} \mathrm{C}$. Before CX3CL1 and CXCL12 determination, brains were homogenized and prepared following the procedure described by Alfonso-Loeches et al. (2010). Frozen brain cortices were homogenized in $250 \mathrm{mg}$ of tissue $/ 0.5 \mathrm{~mL}$ of cold lysis buffer (1\% NP-40, $20 \mathrm{mM}$ Tris - $\mathrm{HCl} \mathrm{pH} 8,130 \mathrm{mM} \mathrm{NaCl}, 10 \mathrm{mM} \mathrm{NaF}$, $10 \mu \mathrm{g} / \mathrm{mL}$ aprotinin, $10 \mu \mathrm{g} / \mathrm{mL}$ leupeptin, $40 \mathrm{mM}$ DTT, $1 \mathrm{mM}$ Na3VO4, and $10 \mathrm{mM}$ PMSF). Brain homogenates were kept on ice for $30 \mathrm{~min}$ and centrifuged at the maximum speed for $15 \mathrm{~min}$; the supernatant was collected and protein levels were determined by the Bradford assay from ThermoFisher (Ref: 23227).

\subsection{Determination of CX3CL1 and CXCL12 levels}

To determine the CX3CL1 and CXCL12 concentration on tissues, we used a Mouse CX3CL1 ELISA Kit obtained from Abcam (Ref: ab100683) and a Mouse CXCL12 Kit obtained from Abcam (Ref: ab100741) that were used following the manufacturer's instructions.

To determine the absorbance, we employed an iMark microplate reader (Bio-RAD) controlled by Microplate Manager 6.2 software. The optical density was read at $450 \mathrm{~nm}$ and final results were calculated using a standard curve following the manufacturer's instructions and expressed as ng/mg for CX3CL1 and as pg/mg for CXCL12 (tissues).

\subsection{Statistical analysis}

The data of the ethological analyses of opponent and intruder mice were analyzed by a two-way ANOVA with a one between-subjects variable-Exercise (with or without physical exercise)-and a one within variable-RSD encounter-with two levels: first and fourth RSD.

To analyze acquisition of EtOH SA, a three-way ANOVA was performed with a two between-subjects variable - Stress (EXP or RSD) and Exercise (with or without wheel access)-and a within-subjects variable-Days, with five levels of FR1 or FR3-followed by the Student's-Newman - Keuls test to compare the groups at different time points of the oral self-administration paradigm. A two-way ANOVA was employed to compare the effects of RSD on the number of active responses, breaking point values and ethanol consumption during PR with two between-subjects variable-Stress (EXP or RSD) and Wheel (with or without physical exercise).

Pearson's coefficient was calculated to determine possible relationships between the EtOH consumption variable (during FR1, FR3 or PR schedules) and ethological analyses of the behaviors exhibited by the intruder mice during RSD (first and fourth).

Data related to chemokine concentrations were analyzed by a oneway ANOVA. In the first set of animals, we analyzed the effects of RSD using an ANOVA with one between-subjects variable-Stress, with four levels (Control, first RSD, fourth RSD, 3 Weeks). For the second set of animals, after SA procedure, we used a two-way ANOVA, with two between-subjects variable-Stress (EXP or RSD) and Wheel (with or without physical exercise). The ANOVAs were followed by a Bonferroni's post-hoc test. The results are reported as mean \pm S.E.M. All analyses were performed using SPSS v24.

Cohen's d effect sizes were calculated for all statistically different comparisons. Effect sizes were classified as small ( $d=0.20-0.49$ ), moderate $(d=0.50-0.79)$, and large $(d \geqslant 0.80)$ (Cohen, 2013).

\section{Results}

\subsection{VWR did not affect behaviors during RSD}

The ANOVA revealed a significant effect of the variable Day for Defensive/Submissive $[\mathrm{F}(1,18)=50.932 ; \mathrm{p}=0.000]$, for Attack $[\mathrm{F}$ $(1,18)=16.357 ; \mathrm{p}=0.001]$, and Threat $[\mathrm{F}(1,18)=5.872 ; \mathrm{p}=0.026]$ behaviors (Table 1). All mice showed an increase of the time spent in these behaviors in the last RSD compared to the first ( $\mathrm{p}=0.001, d=$ $2.244 ; \mathrm{p}=0.001, d=1.290$; and $\mathrm{p}=0.026, d=0.557$ respectively).

\subsection{RSD increase CX3CL1 and CXCL12 levels in the striatum}

The ANOVA indicated that the exposure to RSD induced a significant increase in CX3CL1 $[\mathrm{F}(3,28)=3.988 ; \mathrm{p}=0.017]$ and CXCL12 $[\mathrm{F}(3,28)=5.304 ; \mathrm{p}=0.005]$ protein levels in the Striatum (Fig. $2 \mathrm{a}$

Table 1

Ethological analyses of the RSD.

\begin{tabular}{|c|c|c|c|c|c|c|}
\hline & & \multirow[b]{2}{*}{ Encounters } & \multicolumn{2}{|c|}{ Without exercise } & \multicolumn{2}{|c|}{ With exercise (VWR) } \\
\hline & & & First & Fourth & First & Fourth \\
\hline & & Latency & $8 \pm 4$ & $12 \pm 10$ & $5 \pm 1$ & $8 \pm 3$ \\
\hline \multicolumn{7}{|l|}{ Intruder mice } \\
\hline & Defense/submission & Time $(s)$ & $51 \pm 11$ & $106 \pm 10^{* * * *}$ & $44 \pm 7$ & $105 \pm 6^{* * *}$ \\
\hline & & Latency & $21 \pm 13$ & $5 \pm 2$ & $10 \pm 2$ & $5 \pm 2$ \\
\hline \multicolumn{7}{|l|}{ Opponent mice } \\
\hline & Attack & Time $(s)$ & $54 \pm 5$ & $83 \pm 11^{* * *}$ & $52 \pm 5$ & $84 \pm 9^{* * * *}$ \\
\hline & & Latency & $6 \pm 3$ & $2 \pm 1$ & $3 \pm 1$ & $3 \pm 1$ \\
\hline
\end{tabular}

Results are presented as mean values \pm SEM. ${ }^{*} \mathrm{p}<0.05$; ${ }^{* * *} \mathrm{p}<0.001$ differences between first and fourth RSD. 
a)

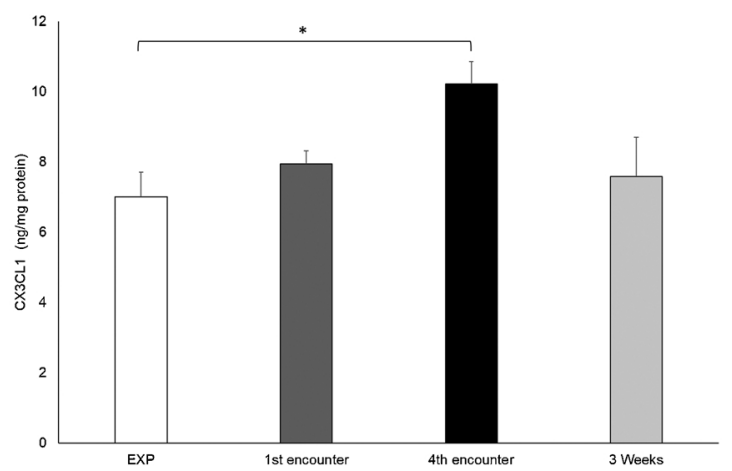

b)

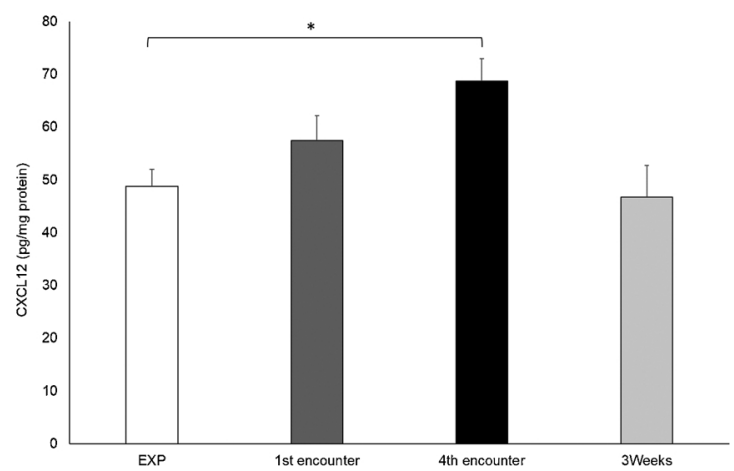

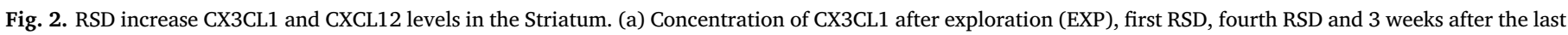

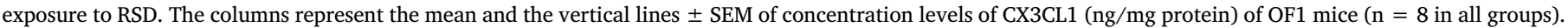

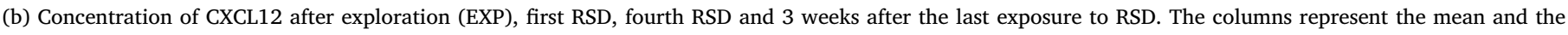
vertical lines \pm SEM of concentration levels of CXCL12 (pg/mg protein) of OF1 mice ( $=8$ in all groups). *p $<0.05$ with respect EXP group.

and $\mathrm{b})$ after the fourth RSD compared to the control group ( $\mathrm{p}=0.019$; $d=1.831$ for CX3CL1; $\mathrm{p}=0.019 ; d=1.998$ for CXCL12).

\subsection{VWR counteracts the increase in ethanol oral self-administration induced by RSD}

The analyses of the acquisition and substitution phases of the selfadministration can be found on the supplementary data.

The ANOVA for the number of active responses during the FR1 schedule of EtOH SA revealed a significant effect of the interactions Days $\times$ Stress $[\mathrm{F}(4,208)=4.024 ; \mathrm{p}=0.032]$ and Stress $\times$ Exercise $[\mathrm{F}$ $(1,52)=4.959 ; \mathrm{p}=0.030$ ] (Fig. $2 \mathrm{a}$ ). The post-hoc comparison showed that active responses were lower on day 1 compared to day $2(\mathrm{p}=0.05$; $d=0.509), 3(\mathrm{p}=0.001 ; d=0.619)$ and $5(\mathrm{p}=0.047 ; d=0.356)$ only in defeated animals. Defeated animals (RSD group) showed higher number of active responses than controls (EXP) ( $\mathrm{p}=0.000 ; d=1.31$ ), as well as the defeated mice exposed to wheels (RSD + Wheel) (p = $0.000 ; d=1.293$ ). With respect to EtOH consumption, the ANOVA revealed a significant effect of the interaction Stress $\times$ Exercise ([F $(1,52)=10.124 ; p=0.002]$ (Fig. 2b). The post-hoc comparison showed that defeated animals (RSD) showed higher EtOH consumption rates than controls (EXP) ( $\mathrm{p}=0.000 ; d=1.566)$ and the defeated mice exposed to wheels (RSD + Wheel) $(\mathrm{p}=0.000 ; d=1.288)$.

During the FR3 schedule, the ANOVA revealed a significant effect of the variable Days $[\mathrm{F}(4,52)=5.387 ; \mathrm{p}=0.000]$ and variable Exercise $[\mathrm{F}(1,52)=4.959 ; \mathrm{p}=0.030]$ for the number of active responses (Fig. 2a). The post-hoc comparison showed a lower number of active responses on day 1 with respect to days $2(\mathrm{p}=0.003 ; d=0.461), 3$ (p $=0.017 ; d=0.417)$ and $4(\mathrm{p}=0.023 ; d=0.398)$. A lower number of active responses was observed in animals that had had access to wheels $(\mathrm{EXP}+$ Wheel and RSD + Wheel $)(\mathrm{p}=0.030 ; d=0.606)$. With respect to EtOH consumption, the ANOVA revealed a significant effect on the interaction Days $\times$ Exercise $[F(4,208)=3.546 ; p=0.008]$. The post-hoc comparison showed that animals without access to a wheel (EXP and RSD) consumed significantly more EtOH with respect to animals with VWR on day 2 ( $\mathrm{p}=0.000 ; d=0.916$ ). In addition, EXP and RSD groups also showed a significant decrease in EtOH consumption during day 1 compared to days 2 ( $\mathrm{p}=0.000 ; d=0.928), 3$ ( $\mathrm{p}=0.005$; $d=0.570)$ and $4(\mathrm{p}=0.011 ; d=0.547)$ (Fig. 3b).

During the progressive ratio, for breaking point values (Fig.3c) the ANOVA revealed a significant effect of the interaction Stress $\times$ Exercise $[\mathrm{F}(1,52)=4.379 ; \mathrm{p}=0.041]$. Post-hoc comparison showed that the breaking point values were higher in defeated animals with respect to the control group ( $\mathrm{p}=0.019 ; d=0.940)$ and RSD + Wheel ( $\mathrm{p}=$ $0.010 ; d=1.068$ ). The ANOVA for the numbers of rewards (Fig.3e) also revealed a significant effect of the variable Exercise $[F(1,52)=$ $8.281(\mathrm{p}=0.006)$, since the groups exposed to VWR showed a lower number of rewards ( $\mathrm{p}=0.006 ; d=0.773$ ). No effects were observed for EtOH consumption (Fig.3d).

\subsection{Passive coping during RSD correlated with stronger ethanol consumption during FR1 schedule}

Pearson's coefficient showed a positive correlation between the time spent in Avoidance/Flee behaviors during the 4th RSD and the average consumption of ethanol during FR1 schedule $(r=0.699 ; p=0.024)$ in RSD group (Fig.4). Those mice that spent more time in avoidance/flee behaviors during RSD showed higher consumption rates of EtOH during the FR1 schedule.

3.5. VWR reverses the increase in striatal levels of CX3CL1 and CXCL12 induced by RSD after EtOH SA

The ANOVA revealed a significant effect of the interaction Stress $\times$ Exercise $[F(1,27)=8.948 ; p=0.006]$ on CX3CL1 protein levels after oral SA of EtOH (Fig. 5a). The post-hoc comparison revealed that defeated animals (RSD) presented significantly higher levels of CX3CL1 than non-stressed animals (EXP) ( $\mathrm{p}=0.009 ; d=2.550)$. In addition, defeated animals exposed to physical exercise (RSD + Wheel) showed significantly lower protein levels compared to defeated animals without access to a running wheel (RSD) ( $\mathrm{p}=0.000 ; d=4.803$ ).

Regarding CXCL12 protein levels, the ANOVA revealed a significant effect of the interaction Stress $\times$ Exercise $[F(1,27)=4.849 ; p=$ 0.036] after oral SA of EtOH (Fig. 5b). The post-hoc comparison revealed that the defeated group (RSD) showed significantly higher protein levels than the non-defeated group (EXP) ( $\mathrm{p}=0.001 ; d=2.213$ ). Higher levels of CXCL12 were obtained in the defeated group without access to the running wheel (RSD) compared to defeated group with VWR (RSD + Wheel) $(\mathrm{p}=0.002 ; d=2.163)$.

\section{Discussion}

The present study confirmed that social stress experienced during adulthood increases consumption and motivation for ethanol and that VWR reverted this effect. In addition, we corroborated that RSD produces a neuroinflammatory response by increasing protein levels of the chemokines CX3CL1 and CXCL12. VWR was also able to revert the neuroinflammatory response caused by stress and exposure to ethanol.

In a previous study from our laboratory, we observed that mice subjected to social stress during adolescence showed an increase in consumption and motivation for ethanol in the oral SA paradigm (Rodríguez-Arias et al., 2017). Those results agree with the results 
a)

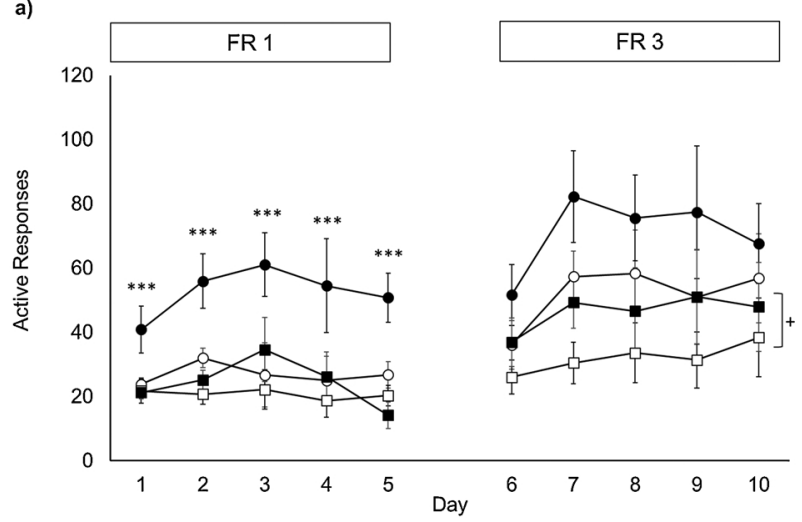

b)

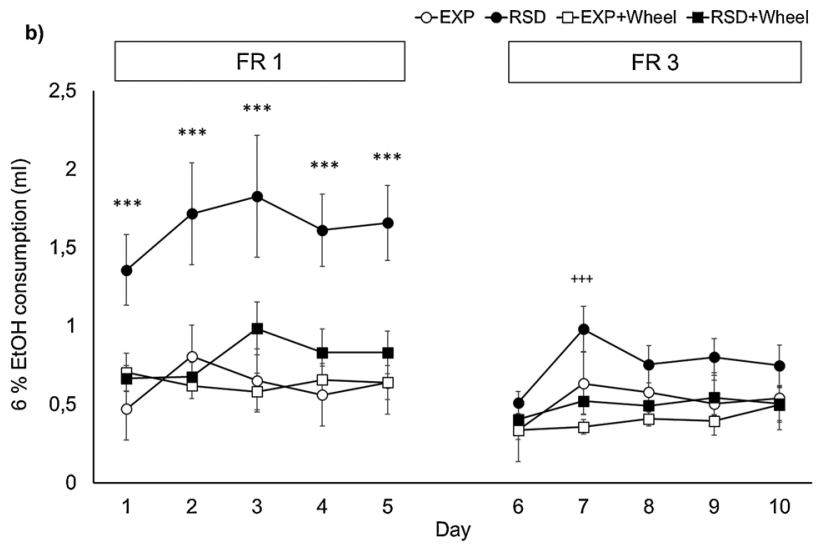

Progressive Ratio

c)

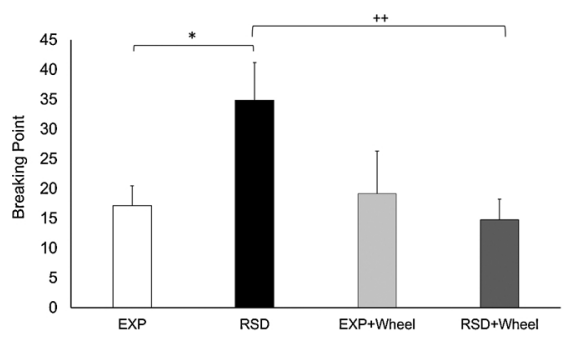

d)

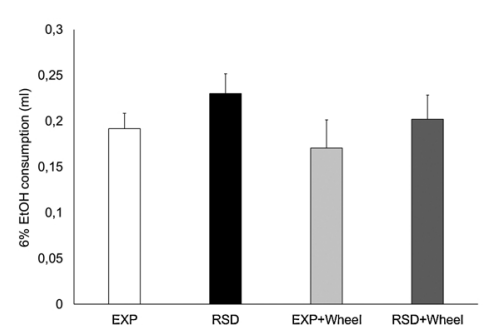

e)

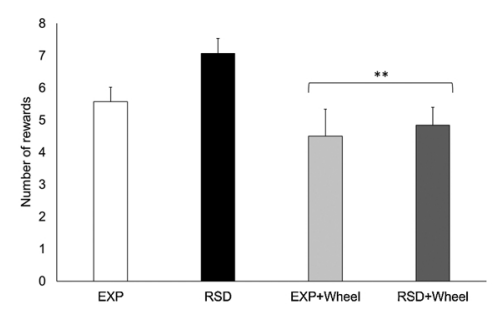

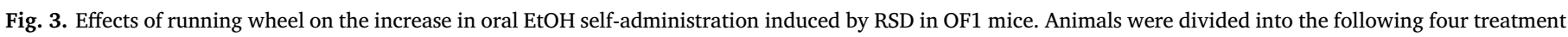

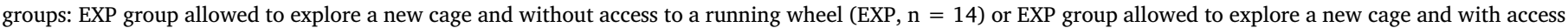

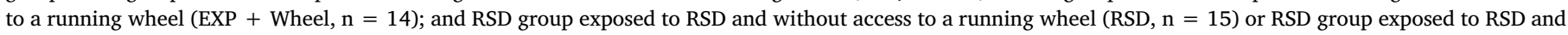

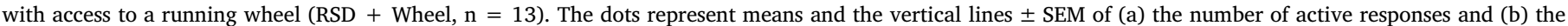

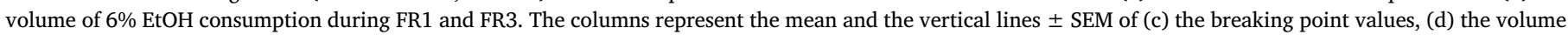

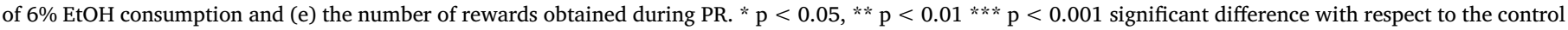

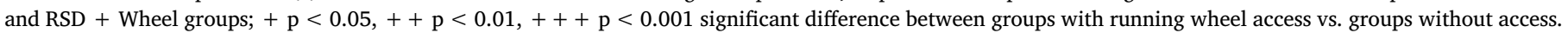

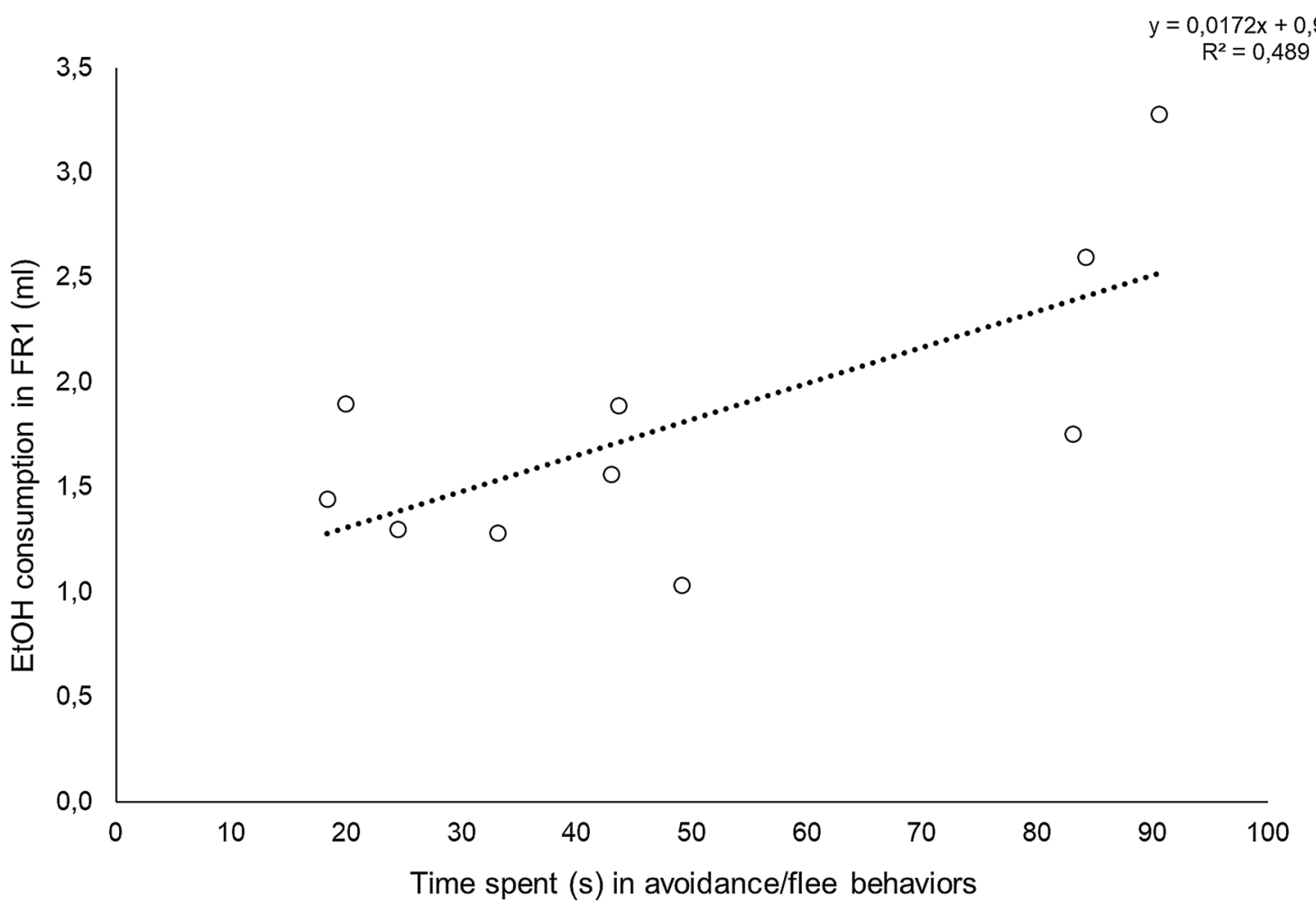

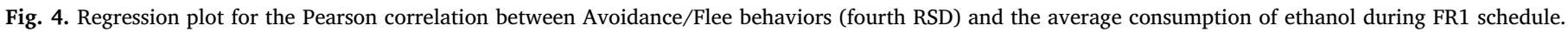
The trend line represents the linear regression of data $(y=0.017 x+0,9639 ; r 2=0.489)$. 


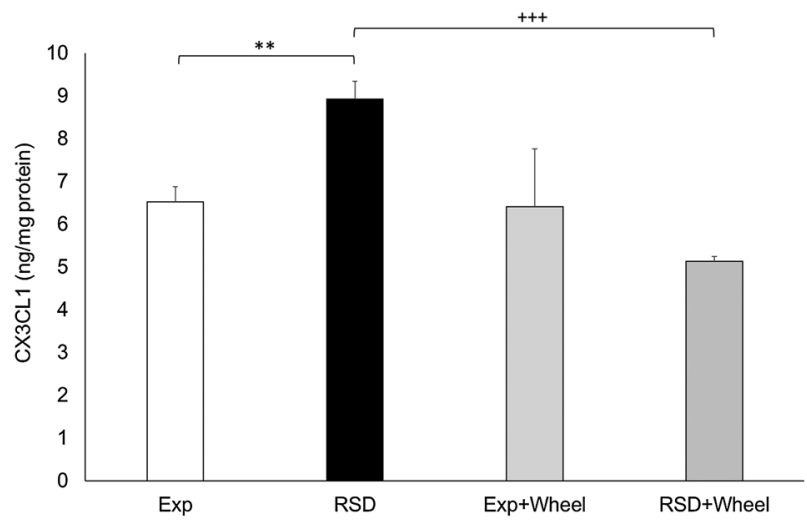

b)

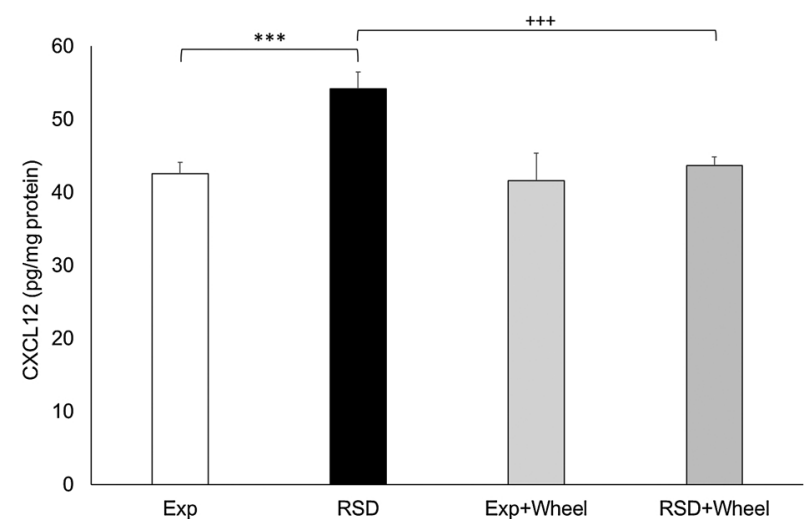

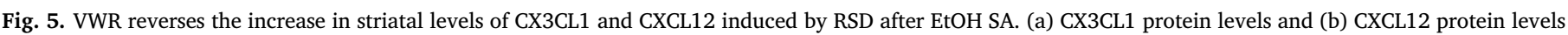

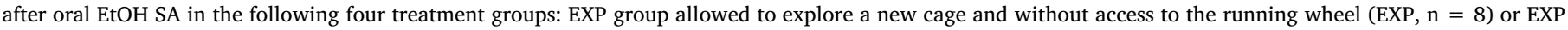

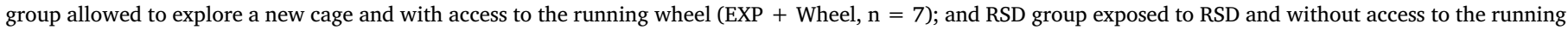

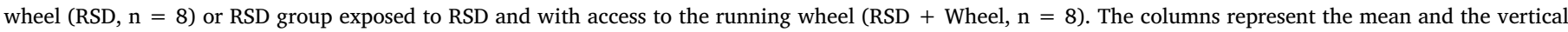

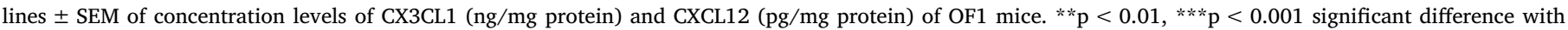
respect to the EXP group; ${ }^{+++} \mathrm{p}<0.001$ significant difference with respect to the corresponding EXP or RSD groups.

obtained in this study in mice defeated during adulthood. The effect of social stress was more apparent during the FR1 phase, although increases were also observed during FR3. The greater the number of active responses needed, the less value the reward has, since there is a loss in the value of delayed rewards (Mazur, 1986; Lagorio and Winger, 2014). During the first day of FR3 a decrease in active responses is characteristically observed because the animals need to learn the new demands. Control non-stressed groups tend to decrease the interest in getting infusions, perhaps because their seeking behavior is not strong (Samson and Czachowski, 2003), although stressed animals work harder to obtain EtOH. Therefore, during the FR3 schedule, it is normal to observe a decrease in the number of infusions received and the total consumption of EtOH with respect to FR1, while defeated animals maintain a greater consumption. Equally, the PR schedule determines the breaking point or limit of active responses that the animal is willing to carry out to obtain EtOH. This progressive pattern of responses is usually indicative of seeking behavior related to motivation (Samson and Czachowski, 2003). We observed that defeated animals showed higher breaking points, although no more EtOH consumption was observed. Taking into account the progressive nature of PR schedules, a small number of substance intakes is usually observed due to the limited session time (in our case, $2 \mathrm{~h}$ ) (Bickel et al., 1990). For this reason, it is difficult to observe differences in consumption. The PR schedule is complementary to the FR schedules, as it links the seeking, motivation, and maintenance behaviors of addictive behavior. In agreement with our results, other studies showed that rodents exposed to SD during adolescence (Marcolin et al., 2019) or adulthood (Deal et al., 2018; Lopez et al., 2016; Riga et al., 2018) showed an increase and escalation in voluntary consumption of ethanol.

Recent studies suggest that coping strategies are associated with resilience or vulnerability to stress (Wood et al., 2015; Chen et al., 2015; Finnell et al., 2017; Pearson-Leary et al., 2017), which seems to be related with neurochemical adaptations that specifically affect the function of the dopamine system and could therefore modify the rewarding efficacy of drugs of abuse (Brodnik et al., 2017). In the present study, we have observed that those animals that spent more time in avoidance and flee behaviors during the last SD presented higher EtOH intake. We have obtained similar results in a previous study (RódenasGonzález et al., 2020), where we observed a positive correlation between flight and avoidance behaviors and the increase in the conditioned rewarding effects of cocaine in the CPP. These results confirm that active coping and adequate adaptation to stress reduces the increase in the rewarding effects of drugs of abuse induced by social stress. Other studies have also confirmed that mice showing active coping strategies show less anhedonia (Wood et al., 2015), less anxiety and greater social interaction (Duclot et al., 2011; Hollis et al., 2011; Kumar et al., 2014). In this work, we hypothesized that controlled physical activity could reduce the effects of RSD. VWR is a rodent model that mimics several aspects of human physical exercise training (Mul et al., 2018). There are no previous studies where VWR was used to intervene on ethanol consumption and motivation induced by social stress, but the effect of physical exercise on ethanol consumption has been studied in various paradigms of voluntary consumption of ethanol, such as TBC or the free-choice paradigm. In general, these studies show lower consumption rates of alcohol in male (Ehringer et al., 2009; Hammer et al., 2010) and female rodents (Piza-Palma et al., 2014) with access to the running wheel. However, a recent study pointed out that the removal of access to exercise appeared to enhance ethanol intake/ preference (Lynch et al., 2019).

On the other hand, physical exercise has a well-documented beneficial effect on stress-related mental disorders. VWR counteracted the development of social avoidance and anhedonia after chronic SD stress (Mul et al., 2018; Zhang et al., 2019). Likewise, VWR attenuated the increased neuroendocrine response induced by social isolation stress (Watanasriyakul et al., 2019) and counteracted the behavioral impairments induced by uncontrollable stress (Greenwood et al., 2003, 2012, 2013; Tanner et al., 2019). The relationship between stress and exercise is bidirectional, as Parra-Montes de Oca et al. (2019) have recently reported that chronic stress decreases the metabolic response to voluntary exercise characterized by the loss of white adipose tissue depots.

Our study showed that exposure to VWR was capable of decreasing the long-lasting increase in ethanol intake induced by RSD. This counteracting action seems to be specific to the stress-induced effect, as no differences in ethanol intake were observed between the two nonstressed groups, meaning that exposure to VWR did not affect basal ethanol intake. In addition, the ethological analyses of RSD showed no differences in opponent or intruder mice behaviors depending on the exposure to VWR, meaning that previous exposure to exercise before each RSD did not affect social stress.

Inflammatory stimuli induced the release of inflammatory cytokines as well as chemokines that functioned as chemo-attractants, presenting homeostatic and/or inflammatory functions (Koper et al., 2018). SD have been linked to an increase of the neuroimmune response, including the activation of microglia (Wohleb et al., 2011, 2014; Lehmann et al., 2016; Rodríguez-Arias et al., 2018), the increase in BBB 
permeability (Rodríguez-Arias et al., 2016), and the increase of IL-6 levels in plasma and the striatum (Ferrer-Pérez et al., 2018). We have now corroborated these results, showing that RSD also induced an increase in the chemokines CX3CL1 and CXCL12 after the fourth RSD.

There is no consensus whether CX3CL1 is an inflammatory or a proinflammatory chemokine (Rahman et al., 2011; Mecca et al., 2018). CX3CL1 signaling through its receptor Cx3cr1 which is only expressed in microglia, being critical for the microglia-neuron cross-talk (Jones et al., 2010; Lauro et al., 2015; Poniatowski et al., 2017). The stressinduced changes in CX3CL1 are not clear, as discrepant results have been described. Adult male rats exposed to chronic mild stress for 2 weeks not only showed an increase in CX3CL1 expression in the dorsal hippocampus, but also a decreased expression in the prefrontal cortex (Rossetti et al., 2016). Moreover, the same authors observed increases or decreases in CX3CL1 expression in the hippocampus after seven weeks of chronic mild stress. Although we have reported in the present study an increase of striatal CX3CL1 levels after the fourth RSD, we obtained in a recent report the opposite effect, following the same experimental procedure with a decrease in CX3CL1 levels in the striatum and no changes in the hippocampus (Montagud-Romero et al., 2020). The use of a different strain of mice (OF1 or C57BL/6NTac) could be responsible for these discrepant results. Since OF1 is a particularly territorial strain of mice, the loss of social encounters could have had a more intense stress effect leading to a higher neuroinflammation response. In addition, in the present study, we observed an increase in CX3CL1 levels in defeated mice after ethanol oral self-administration.

With respect to CXCL12, this chemokine is ubiquitously expressed and binding to two receptors, CXCR4 and ACKR3. The CXCL12/CXCR4/ ACKR3 axis plays key roles in many physiological and pathological processes, including embryogenesis, wound healing processes, angiogenesis, homeostasis and it also participates in the progression of inflammation (McCandless et al., 2006; Niraula et al., 2018; GarcíaCuesta et al., 2019). Therefore, an increased expression of CXCL12 has been described in many inflammatory and autoimmune diseases (Wei et al., 2012; Rizzo et al., 2013), which suggests an inflammatory role. In agreement with this role, we observed that our RSD protocol induced a significant increase of this chemokine after the fourth defeat. However, Sawicki et al. (2015) did not observe changes in the CXCL12 gen-expression or a reduction of CXCL12 mRNA levels in enriched microglia/ macrophages immediately after the last exposure to SD.

Many studies show that a prolonged consumption of ethanol produces increases in brain chemokine levels in rodents (Pascual et al., 2015; Somkuwar et al., 2016). In our study, both chemokines were significantly increased after oral ethanol SA in defeated animals in comparison with those non-stressed.

The increase in chemokines after EtOH oral SA, which was only found in the defeated group that had no access to VWR, suggests a sensitization of the neuroinflammatory response. Stressed mice exposed to ethanol presented higher levels of chemokines that are not observed in non-stressed animal or in those defeated but exposed to VWR. These differences could be due to the less amount of ethanol ingested by these mice, since it is well known that ethanol is per se a potent neuroinflammatory factor (Montesinos et al., 2016; Pascual et al., 2015). However, we have previously reported that defeated mice showed elevated levels of the pro-inflammatory cytokine IL- 6 that were not observed in control mice after having been exposed to the same doses of cocaine (Ferrer-Pérez et al., 2019). Therefore, although we cannot prevent control mice to ingest less ethanol, we suggest that social stress sensitized the inflammatory system to further responses. Confirming these results, we have previously reported increases in these chemokines after cocaine administration in mice (Araos et al., 2015), In addition, we observed a decrease in CXCL12 chemokine in abstinent cocaine users without changes in CX3CL1 plasma levels, although these levels positively correlated with the cocaine symptom severity for cocaine abuse/dependence (Araos et al., 2015). Although we did not measure the acute effect of VWR after each RSD, we observed that after oral EtOH SA, VWR significantly decreased the striatal levels of chemokines (CX3CL1 and CXCL12), showing levels similar to those in the control group. In contrast with this effect, there are several reports showing an increased neuroinflammatory response in animals exposed to physical exercise, in some cases forced or maintained for $24 \mathrm{~h}$ a day (Svensson et al., 2016; Pinto et al., 2019). The literature suggests that moderate-intensity exercise may be optimal in decreasing neuroinflammatory markers (Henrique et al., 2018; Paolucci et al., 2018). In agreement with our results, some studies have shown the positive effects of controlled physical exercise on stress (Mul et al., 2018; Ignácio et al., 2019), addiction (Somkuwar et al., 2016) or Alzheimer's disease (He et al., 2017; Jensen et al., 2019; Małkiewicz et al., 2019). Physical exercise interacts with stress and neuroinflammation depending on the intensity. Several studies have observed that VWR reduces the levels of corticosterone and glucocorticoid receptors, attenuating the negative effects of chronic stress (Zheng et al., 2006; Ignácio et al., 2019; Lynch et al., 2019; Watanasriyakul et al., 2019). The inhibition of the excess production of corticosterone can attenuate the inflammatory response of stress (Niraula et al., 2018). Only few studies have examined the effect of exercise and chemokine levels. For example, long-term wheel performance decreases the western diet increased in the gene expression of CXCL10 and CCL2 (Carlin et al., 2016).

\section{Conclusions}

In conclusion, our results suggest that VWR is a beneficial environmental intervention that is capable of blocking the increased ethanol intake and the neuroinflammation induced by social stress. Our work highlights the complexity of the brain mechanisms involved in the inflammatory process in response to social stress. To sum up, VWR could be a promising preventive and therapeutic target to avoid and reduce the detrimental effects induced by social stress.

\section{Data availability}

The datasets generated for this study are available on request to the corresponding author.

\section{Funding}

This work was supported by the Ministerio de Economía, Industria y Competitividad, Gobierno de España (MINECO), Dirección General de Investigación, PSI2014-51847-R and PSI 2017-83023-R; Instituto de Salud Carlos III, Red de Trastornos Adictivos (RTA; RETICS RD16/ 0017/0007) and Unión Europea, Fondos FEDER "A way to build Europe." Reguilón, MD received FPI grant from the Spanish Ministry of Science, Innovation and Universities (PRE2018-084159).

The authors have no possible conflict of interest in the carrying out and reporting of this research.

All the authors have made a substantial contribution for the conception, design, and drafting the article.

All the authors have approved the version to be submitted.

\section{Declaration of competing interest}

The authors declare that the research was conducted in the absence of any commercial or financial relationships that could be construed as a potential conflict of interest.

\section{CRediT authorship contribution statement}

M.D. Reguilón: Conceptualization, Formal analysis, Investigation, Methodology, Validation, Writing - original draft. C. Ferrer-Pérez: Formal analysis, Investigation, Software, Validation, Writing - original draft. R. Ballestín: Investigation, Methodology. J. Miñarro: Conceptualization, Funding acquisition, Project administration, 
Resources, Supervision, Writing - review \& editing. M. RodríguezArias: Conceptualization, Funding acquisition, Methodology, Project administration, Resources, Software, Supervision, Writing - original draft, Writing - review \& editing.

\section{Acknowledgments}

We wish to thank Guillem Chuliá for his English language editing.

\section{Appendix A. Supplementary data}

Supplementary material related to this article can be found, in the online version, at doi:https://doi.org/10.1016/j.drugalcdep.2020. 108004.

\section{References}

Alfonso-Loeches, S., Pascual-Lucas, M., Blanco, A.M., Sanchez-Vera, I., Guerri, C., 2010. Pivotal role of TLR4 receptors in alcohol-induced neuroinflammation and brain damage. J. Neurosci. 30, 8285-8295. https://doi.org/10.1523/JNEUROSCI.0976-10. 2010.

Araos, P., Pedraz, M., Serrano, A., Lucena, M., Barrios, V., García-Marchena, N., CamposCloute, R., Ruiz, J.J., Romero, P., Suárez, J., Baixeras, E., de la Torre, R., Montesinos, J., Guerri, C., Rodríguez-Arias, M., Miñarro, J., Martínez-Riera, R., Torrens, M., Chowen, J.A., Argente, J., Mason, B.J., Pavón, F.J., Rodríguez de Fonseca, F., 2015. Plasma profile of pro-inflammatory cytokines and chemokines in cocaine users under outpatient treatment: influence of cocaine symptom severity and psychiatric co-morbidity. Addict. Biol. 20, 756-772. https://doi.org/10.1111/adb.12156.

Beutel, T.F., Zwerenz, R., Michal, M., 2018. Psychosocial stress impairs health behavior in patients with mental disorders. BMC Psychiatry 18, 375. https://doi.org/10.1186/ s12888-018-1956-8.

Bickel, W.K., DeGrandpre, R.J., Higgins, S.T., Hughes, J.R., 1990. Behavioral economics of drug self-administration. I. Functional equivalence of response requirement and drug dose. Life Sci. 47 (17), 1501-1510. https://doi.org/10.1016/0024-3205(90) 90178-t.

Brodnik, Z.D., Double, M., España, R.A., Jaskiw, G.E., 2017. L-tyrosine availability affects basal and stimulated catecholamine indices in prefrontal cortex and striatum of the rat. Neuropharmacology 123, 159-174. https://doi.org/10.1016/j.neuropharm. 2017.05.030.

Calcia, M.A., Bonsall, D.R., Bloomfield, P.S., Selvaraj, S., Barichello, T., Howes, O.D., 2016. Stress and neuroinflammation: A systematic review of the effects of stress on microglia and the implications for mental illness. Psychopharmacology (Berl.) 233, 1637-1650. https://doi.org/10.1007/s00213-016-4218-9.

Carlin, J.L., Grissom, N., Ying, Z., Gomez-Pinilla, F., Reyes, T.M., 2016. Voluntary exercise blocks western diet-induced gene expression of the chemokines CXCL10 and CCL2 in the prefrontal cortex. Brain Behav. Immun. 58, 82-90. https://doi.org/10. 1016/j.bbi.2016.07.161.

Chen, R., Kelly, G., Sengupta, A., Heydendael, W., Nicholas, B., Beltrami, S., Luz, S., Peixoto, L., Abel, T., Bhatnagar, S., 2015. MicroRNAs as biomarkers of resilience or vulnerability to stress. Neuroscience 305, 36-48. https://doi.org/10.1016/j. neuroscience.2015.07.045

Cohen, J., 2013. Statistical Power Analysis for the Behavioural Sciences. Academic Press.

Covington III, H., Miczek, K., 2001. Repeated social-defeat stress, cocaine or morphine. Psychopharmacology 158, 388-398. https://doi.org/10.1007/s002130100858.

Darlington, T.M., McCarthy, R.D., Cox, R.J., Ehringer, M.A., 2014. Mesolimbic transcriptional response to hedonic substitution of voluntary exercise and voluntary ethanol consumption. Behav. Brain Res. 259, 313-320. https://doi.org/10.1016/j. bbr.2013.11.011.

Darlington, T.M., McCarthy, R.D., Cox, R.J., Miyamoto-Ditmon, J., Gallego, X., Ehringer, M.A., 2016. Voluntary wheel running reduces voluntary consumption of ethanol in mice: identification of candidate genes through striatal gene expression profiling Genes Brain Behav. 15, 474-490. https://doi.org/10.1111/gbb.12294.

Deal, A.L., Konstantopoulos, J.K., Weiner, J.L., Budygin, E.A., 2018. Exploring the consequences of social defeat stress and intermittent ethanol drinking on dopamine dynamics in the rat nucleus accumbens. Sci. Rep. 8, 332. https://doi.org/10.1038/ s41598-017-18706-y.

Duclot, F., Hollis, F., Darcy, M.J., Kabbaj, M., 2011. Individual differences in noveltyseeking behavior in rats as a model for psychosocial stress-related mood disorders. Physiol. Behav. 104, 296-305. https://doi.org/10.1016/j.physbeh.2010.12.014.

Ehringer, M.A., Hoft, N.R., Zunhammer, M., 2009. Reduced alcohol consumption in mice with access to a running wheel. Alcohol 43, 443-452. https://doi.org/10.1016/j. alcohol.2009.06.003.

Ferrer-Pérez, C., Martinez, T.E., Montagud-Romero, S., Ballestín, R., Reguilón, M.D. Miñarro, J., Rodríguez-Arias, M., 2018. Indomethacin blocks the increased conditioned rewarding effects of cocaine induced by repeated social defeat. PLoS One 13, e0209291. https://doi.org/10.1371/journal.pone.0209291.

Ferrer-Pérez, C., Castro-Zavala, A., Luján, M.Á, Filarowska, J., Ballestín, R., Miñarro, J., Valverde, O., Rodríguez-Arias, M., 2019. Oxytocin prevents the increase of cocainerelated responses produced by social defeat. Neuropharmacology 146, 50-64. https://doi.org/10.1016/j.neuropharm.2018.11.011.
Finnell, J.E., Wood, S.K., 2016. Neuroinflammation at the interface of depression and cardiovascular disease: evidence from rodent models of social stress. Neurobiol. Stress 4, 1-14. https://doi.org/10.1016/j.ynstr.2016.04.001.

Finnell, J.E., Lombard, C.M., Padi, A.R., Moffitt, C.M., Wilson, L.B., Wood, C.S., Wood, S.K., 2017. Physical versus psychological social stress in male rats reveals distinct cardiovascular, inflammatory and behavioral consequences. PLoS One 12, e0172868. https://doi.org/10.1371/journal.pone.0172868.

García-Cuesta, E.M., Santiago, C.A., Vallejo-Díaz, J., Juarranz, Y., Rodríguez-Frade, J.M., Mellado, M., 2019. The role of the CXCL12/CXCR4/ACKR3 axis in autoimmune diseases. Front. Endocrinol. (Lausanne) 10, 585. https://doi.org/10.3389/fendo. 2019.00585.

Greenwood, B.N., Foley, T.E., Day, H.E.W., Campisi, J., Hammack, S.H., Campeau, S., Maier, S.F., Fleshner, M., 2003. Freewheel running prevents learned helplessness/ behavioral depression: role of dorsal raphe serotonergic neurons. J. Neurosci. 23, 2889-2898. https://doi.org/10.1523/JNEUROSCI.23-07-02889.2003.

Greenwood, B.N., Foley, T.E., Le, T.V., Strong, P.V., Loughridge, A.B., Day, H.E.W., Fleshner, M., 2011. Long-term voluntary wheel running is rewarding and produces plasticity in the mesolimbic reward pathway. Behav. Brain Res. 217, 354-362. https://doi.org/10.1016/j.bbr.2010.11.005.

Greenwood, B.N., Loughridge, A.B., Sadaoui, N., Christianson, J.P., Fleshner, M., 2012. The protective effects of voluntary exercise against the behavioral consequences of uncontrollable stress persist despite an increase in anxiety following forced cessation of exercise. Behav. Brain Res. 233, 314-321. https://doi.org/10.1016/j.bbr.2012.05. 017.

Greenwood, B.N., Spence, K.G., Crevling, D.M., Clark, P.J., Craig, W.C., Fleshner, M., 2013. Exercise-induced stress resistance is independent of exercise controllability and the medial prefrontal cortex. Eur. J. Neurosci. 37, 469-478. https://doi.org/10. 1111/ejn.12044.

Hammer, S.B., Ruby, C.L., Brager, A.J., Prosser, R.A., Glass, J.D., 2010. Environmental modulation of alcohol intake in hamsters: effects of wheel running and constant light exposure. Alcohol Clin. Exp. Res. 34, 1651-1658. https://doi.org/10.1111/j.15300277.2010.01251.x.

He, X.F., Liu, D.X., Zhang, Q., Liang, F.Y., Dai, G.Y., Zeng, J.S., Pei, Z., Xu, G.Q., Lan, Y., 2017. Voluntary exercise promotes glymphatic clearance of amyloid beta and reduces the activation of astrocytes and microglia in aged mice. Front. Mol. Neurosci. 10, 144. https://doi.org/10.3389/fnmol.2017.00144.

Heffner, T.G., Hartman, J.A., Seiden, L.S., 1980. A rapid method for the regional dissection of the rat brain. Pharmacol. Biochem. Behav. 13, 453-456. https://doi.org/ 10.1016/0091-3057(80)90254-3.

Henrique, J.S., França, E.F., Cardoso, Fd.S., Serra, F.T., de Almeida, A.A., Fernandes, J., Arida, R.M., Gomes da Silva, S., 2018. Cortical and hippocampal expression of inflammatory and intracellular signaling proteins in aged rats submitted to aerobic and resistance physical training. Exp. Gerontol. 110, 284-290. https://doi.org/10.1016/j. exger.2018.06.025.

Hollis, F., Duclot, F., Gunjan, A., Kabbaj, M., 2011. Individual differences in the effect of social defeat on anhedonia and histone acetylation in the rat hippocampus. Horm. Behav. 59, 331-337. https://doi.org/10.1016/j.yhbeh.2010.09.005.

Holly, E.N., Boyson, C.O., Montagud-Romero, S., Stein, D.J., Gobrogge, K.L., DeBold, J.F., Miczek, K.A., 2016. Episodic social stress-escalated cocaine self-administration: role of phasic and tonic corticotropin releasing factor in the anterior and posterior ventral tegmental area. J. Neurosci. 36, 4093-4105. https://doi.org/10.1523/JNEUROSCI. 2232-15.2016.

Hwa, L.S., Holly, E.N., DeBold, J.F., Miczek, K.A., 2016. Social stress-escalated intermittent alcohol drinking: modulation by CRF-R1 in the ventral tegmental area and accumbal dopamine in mice. Psychopharmacology 233, 681-690. https://doi.org/ 10.1007/s00213-015-4144-2.

Ignácio, Z.M., da Silva, R.S., Plissari, M.E., Quevedo, J., Réus, G.Z., 2019. Physical exercise and neuroinflammation in major depressive disorder. Mol. Neurobiol. 56, 8323-8335. https://doi.org/10.1007/s12035-019-01670-1.

Jensen, C.S., Bahl, J.M., Østergaard, L.B., Høgh, P., Wermuth, L., Heslegrave, A., Zetterberg, H., Heegaard, N.H.H., Hasselbalch, S.G., Simonsen, A.H., 2019. Exercise as a potential modulator of inflammation in patients with Alzheimer's disease measured in cerebrospinal fluid and plasma. Exp. Gerontol. 121, 91-98. https://doi.org/ 10.1016/j.exger.2019.04.003.

Jones, B.A., Beamer, M., Ahmed, S., 2010. Fractalkine/CX3CL1: a potential new target for inflammatory diseases. Mol. Interv. 10, 263-270. https://doi.org/10.1124/mi.10. 5.3 .

Karlsson, C., Schank, J.R., Rehman, F., Stojakovic, A., Björk, K., Barbier, E., Solomon, M., Tapocik, J., Engblom, D., Thorsell, A., Heilig, M., 2017. Proinflammatory signaling regulates voluntary alcohol intake and stress-induced consumption after exposure to social defeat stress in mice. Addict. Biol. 22, 1279-1288. https://doi.org/10.1111/ adb.12416.

Keogh, B., Parker, A.E., 2011. Toll-like receptors as targets for immune disorders. Trends Pharmacol. Sci. 32, 435-442. https://doi.org/10.1016/j.tips.2011.03.008.

Koob, G.F., Schulkin, J., 2019. Addiction and stress: an allostatic view. Neurosci. Biobehav. Rev. 106, 245-262. https://doi.org/10.1016/j.neubiorev. 2018.09.008.

Koper, O.M., Kamińska, J., Sawicki, K., Kemona, H., 2018. CXCL9, CXCL10, CXCL11, and their receptor (CXCR3) in neuroinflammation and neurodegeneration. Adv. Clin. Exp. Med. 27, 849-856. https://doi.org/10.17219/acem/68846.

Kumar, S., Hultman, R., Hughes, D., Michel, N., Katz, B.M., Dzirasa, K., 2014. Prefrontal cortex reactivity underlies trait vulnerability to chronic social defeat stress. Nat. Commun. 5, 4537. https://doi.org/10.1038/ncomms5537.

Lagorio, C.H., Winger, G., 2014. Random-ratio schedules produce greater demand for i.v. Drug administration than fixed-ratio schedules in rhesus monkeys. Psychopharmacology (Berl.) 231, 2981-2988. https://doi.org/10.1007/s00213-0143477-6. 
Laine, M.A., Sokolowska, E., Dudek, M., Callan, S., Hyytiä, P., Hovatta, I., 2017. Brain activation induced by chronic psychosocial stress in mice. Sci. Rep. 7https://doi.org/ 10.1038/s41598-017-15422-5. 15061-11.

Lauro, C., Catalano, M., Trettel, F., Limatola, C., 2015. Fractalkine in the nervous system: neuroprotective or neurotoxic molecule? Ann. N. Y. Acad. Sci. 1351, 141-148. https://doi.org/10.1111/nyas.12805.

Lehmann, M.H., Torres-Domínguez, L.E., Price, P.J.R., Brandmüller, C., Kirschning, C.J., Sutter, G., 2016. CCL2 expression is mediated by type I IFN receptor and recruits NK and T cells to the lung during MVA infection. J. Leukoc. Biol. 99, 1057-1064. https:// doi.org/10.1189/jlb.4MA0815-376RR.

Lopez, M.F., Anderson, R.I., Becker, H.C., 2016. Effect of different stressors on voluntary ethanol intake in ethanol-dependent and nondependent C57BL/6J mice. Alcohol 51, 17-23. https://doi.org/10.1016/j.alcohol.2015.11.010.

Lynch, C.A., Porter, B., Butler, T.R., 2019. Access to voluntary running wheel exercise: prevention of anxiety-like behavior in chronically stressed rats, but potentiation of ethanol intake/preference. Physiol. Behav. 206, 118-124. https://doi.org/10.1016/j physbeh.2019.03.028.

Małkiewicz, M.A., Szarmach, A., Sabisz, A., Cubała, W.J., Szurowska, E., Winklewski, P.J., 2019. Blood-brain barrier permeability and physical exercise. J. Neuroinflammation 16, 15-16. https://doi.org/10.1186/s12974-019-1403-x.

Marcolin, M.L., Hodges, T.E., Baumbach, J.L., McCormick, C.M., 2019. Adolescent social stress and social context influence the intake of ethanol and sucrose in male rats soon and long after the stress exposures. Dev. Psychobiol. 61, 81-95. https://doi.org/10. 1002/dev.21800.

Mazur, J.E., 1986. Fixed and variable ratios and delays: further tests of an equivalence rule. J. Exp. Psychol. Anim. Behav. Process. 12, 116-124.

McCandless, E.E., Wang, Q., Woerner, B.M., Harper, J.M., Klein, R.S., 2006. CXCL12 limits inflammation by localizing mononuclear infiltrates to the perivascular space during experimental autoimmune encephalomyelitis. J. Immunol. 177, 8053-8064. https://doi.org/10.4049/jimmunol.177.11.8053.

Mecca, C., Giambanco, I., Donato, R., Arcuri, C., 2018. Microglia and aging: the role of the TREM2-DAP12 and CX3CL1-CX3CR1 axes. Int. J. Mol. Sci. 19, 318. https://doi. org/10.3390/ijms19010318.

Miczek, K.A., Faccidomo, S., Almeida, R.M.M., Bannai, M., Fish, E.W., Debold, J.F., 2004. Escalated aggressive behavior: new pharmacotherapeutic approaches and opportunities. Ann. N. Y. Acad. Sci. 1036, 336-355. https://doi.org/10.1196/annals.1330. 021.

Miczek, K.A., Yap, J.J., Covington, H.E., 2008. Social stress, therapeutics and drug abuse: preclinical models of escalated and depressed intake. Pharmacol. Ther. 120, 102-128. https://doi.org/10.1016/j.pharmthera.2008.07.006.

Milior, G., Lecours, C., Samson, L., Bisht, K., Poggini, S., Pagani, F., Deflorio, C., Lauro, C., Alboni, S., Limatola, C., Branchi, I., Tremblay, M.E., Maggi, L., 2016. Fractalkine receptor deficiency impairs microglial and neuronal responsiveness to chronic stress. Brain Behav. Immun. 55, 114-125. https://doi.org/10.1016/j.bbi.2015.07.024.

Montagud-Romero, S., Reguilón, M.D., Roger-Sanchez, C., Pascual, M., Aguilar, M.A., Guerri, C., Miñarro, J., Rodríguez-Arias, M., 2016. Role of dopamine neurotransmission in the long-term effects of repeated social defeat on the conditioned rewarding effects of cocaine. Prog. Neuropsychopharmacol. Biol. Psychiatry 71, 144-154. https://doi.org/10.1016/j.pnpbp.2016.07.008.

Montagud-Romero, S., Montesinos, J., Pavón, F.J., Blanco-Gandia, M.C., Ballestín, R., Rodríguez de Fonseca, F., Miñarro, J., Guerri, C., Rodríguez-Arias, M., 2020. Social defeat-induced increase in the conditioned rewarding effects of cocaine: role of CX3CL1. Prog. Neuropsychopharmacol. Biol. Psychiatry 96, 109753. https://doi.org/ 10.1016/j.pnpbp.2019.109753.

Montagud-Romero, S., Blanco-Gandía, M.C., Reguilón, M.D., Ferrer-Pérez, C., Ballestín, R., Miñarro, J., Rodríguez-Arias, M., 2018. Social defeat stress: mechanisms underlying the increase in rewarding effects of drugs of abuse. Eur. J. Neurosci. 48, 2948-2970. https://doi.org/10.1111/ejn.14127.

Montesinos, J., Alfonso-Loeches, S., Guerri, C., 2016. Impact of the innate immune response in the actions of ethanol on the central nervous system. Alcohol. Clin. Exp. Res. 40, 2260-2270. https://doi.org/10.1111/acer.13208.

Mul, J.D., 2018. Voluntary exercise and depression-like behavior in rodents: are we running in the right direction? J. Mol. Endocrinol. 60, R77-R95. https://doi.org/10. 1530/JME-17-0165.

Mul, J.D., Soto, M., Cahill, M.E., Ryan, R.E., Takahashi, H., So, K., Zheng, J., Croote, D.E., Hirshman, M.F., la Fleur, S., Nestler, E.J., Goodyear, L.J., 2018. Voluntary wheel running promotes resilience to chronic social defeat stress in mice: a role for nucleus accumbens $\Delta$ FosB. Neuropsychopharmacology 43, 1934-1942. https://doi.org/10. 1038/s41386-018-0103-z.

Navarrete, F., Pérez-Ortiz, J.M., Manzanares, J., 2012. Cannabinoid CB2 receptor-mediated regulation of impulsive-like behaviour in DBA/2 mice. Br. J. Pharmacol. 165, 260-273. https://doi.org/10.1111/j.1476-5381.2011.01542.x.

Navarrete, F., Rubio, G., Manzanares, J., 2014. Effects of naltrexone plus topiramate on ethanol self-administration and tyrosine hydroxylase gene expression changes. Addict. Biol. 19, 862-873. https://doi.org/10.1111/adb.12058.

Newman, E., Albrechet-Souza, L., Andrew, P., Auld, J., Burk, K., Hwa, L., Zhang, E.Y. DeBold, J.F., Miczek, K.A., 2018. Persistent escalation of alcohol consumption by mice exposed to brief episodes of social defeat stress: suppression by CRF-R1 antagonism. Psychopharmacology 235, 1807-1820. https://doi.org/10.1007/s00213018-4905-9.

Niraula, A., Wang, Y., Godbout, J.P., Sheridan, J.F., 2018. Corticosterone production during repeated social defeat causes monocyte mobilization from the bone marrow, glucocorticoid resistance, and neurovascular adhesion molecule expression. J. Neurosci. 38, 2328-2340. https://doi.org/10.1523/JNEUROSCI.2568-17.2018.

Norman, K., Seiden, J., Klickstein, J., Han, X., Hwa, L., DeBold, J.F., Miczek, K.A., 2015. Social stress and escalated drug self-administration in mice I. Alcohol and corticosterone. Psychopharmacology 232, 991-1001. https://doi.org/10.1007/ s00213-014-3733-9.

Paolucci, E.M., Loukov, D., Bowdish, D.M.E., Heisz, J.J., 2018. Exercise reduces depression and inflammation but intensity matters. Biol. Psychol. 133, 79-84. https://doi. org/10.1016/j.biopsycho.2018.01.015.

Park, M., Levine, H., Toborek, M., 2016. Exercise protects against methamphetamineinduced aberrant neurogenesis. Sci. Rep. 6, 34111. https://doi.org/10.1038/ srep34111.

Parra-Montes de Oca, M.A., Gutiérrez-Mariscal, M., Salmerón-Jiménez, M.F., Jaimes-Hoy, L., Charli, J., Joseph-Bravo, P., 2019. Voluntary exercise-induced activation of thyroid axis and reduction of white fat depots is attenuated by chronic stress in a sex dimorphic pattern in adult rats. Front. Endocrinol. (Lausanne) 10, 418. https://doi. org $/ 10.3389 /$ fendo.2019.00418.

Pascual, M., Baliño, P., Aragón, C.M.G., Guerri, C., 2015. Cytokines and chemokines as biomarkers of ethanol-induced neuroinflammation and anxiety-related behavior: role of TLR4 and TLR2. Neuropharmacology 89, 352-359. https://doi.org/10.1016/j. neuropharm.2014.10.014.

Pearson-Leary, J., Eacret, D., Chen, R., Takano, H., Nicholas, B., Bhatnagar, S., 2017. Inflammation and vascular remodeling in the ventral hippocampus contributes to vulnerability to stress. Transl. Psychiatry 7, e1160. https://doi.org/10.1038/tp.2017. 122.

Pietrelli, A., Di Nardo, M., Masucci, A., Brusco, A., Basso, N., Matkovic, L., 2018. Lifelong aerobic exercise reduces the stress response in rats. Neuroscience 376, 94-107. https://doi.org/10.1016/j.neuroscience.2018.02.019.

Pinto, A.P., da Rocha, A.L., Kohama, E.B., Gaspar, R.C., Simabuco, F.M., Frantz, F.G., de Moura, L.P., Pauli, J.R., Cintra, D.E., Ropelle, E.R., de Freitas, E.C., da Silva, A.S.R., 2019. Exhaustive acute exercise-induced ER stress is attenuated in IL-6-knockout mice. J. Endocrinol. 240, 181-193. https://doi.org/10.1530/JOE-18-0404.

Piza-Palma, C., Barfield, E.T., Brown, J.A., Hubka, J.C., Lusk, C., Schonhar, C.A., Sweat, S.C., Grisel, J.E., 2014. Oral self-administration of EtOH: sex-dependent modulation by running wheel access in C57BL/6J mice. Alcohol. Clin. Exp. Res. 38, 2387-2395. https://doi.org/10.1111/acer.12519.

Poniatowski, Ł., Wojdasiewicz, P., Krawczyk, M., Szukiewicz, D., Gasik, R., Kubaszewski, Ł., Kurkowska-Jastrzebska, I., 2017. Analysis of the role of CX3CL1 (fractalkine) and its receptor CX3CR1 in traumatic brain and spinal cord injury: insight into recent advances in actions of neurochemokine agents. Mol. Neurobiol. 54, 2167-2188. https://doi.org/10.1007/s12035-016-9787-4.

Rahman, S., Connolly, J.E., Manuel, S.L., Chehimi, J., Montaner, L.J., Jain, P., 2011. Unique cytokine/chemokine signatures for HIV-1 and HCV mono- infection versus coinfection as determined by the luminex ${ }^{\circledR}$ analyses. J. Clin. Cell. Immunol. 2, 1000104. https://doi.org/10.4172/2155-9899.1000104.

Riga, D., Schmitz, L.J.M., van der Harst, J.E., van Mourik, Y., Hoogendijk, W.J.G., Smit, A.B., De Vries, T.J., Spijker, S., 2014. A sustained depressive state promotes a guanfacine reversible susceptibility to alcohol seeking in rats. Neuropsychopharmacology 39, 1115-1124. https://doi.org/10.1038/npp.2013.311.

Riga, D., Schmitz, L.J.M., van Mourik, Y., Hoogendijk, W.J.G., De Vries, T.J., Smit, A.B., Spijker, S., 2018. Stress vulnerability promotes an alcohol-prone phenotype in a preclinical model of sustained depression. Addict. Biol. 25, e12701. https://doi.org/ 10.1111/adb.12701.

Rizzo, P., Perico, N., Gagliardini, E., Novelli, R., Alison, M.R., Remuzzi, G., Benigni, A., 2013. Nature and mediators of parietal epithelial cell activation in glomerulonephritides of human and rat. Am. J. Pathol. 183, 1769-1778. https://doi.org/10. 1016/j.ajpath.2013.08.008.

Roberts, A.J., Gold, L.H., Polis, I., McDonald, J.S., Filliol, D., Kieffer, B.L., Koob, G.F., 2001. Increased ethanol self-administration in $\delta$-opioid receptor knockout mice. Alcohol. Clin. Exp. Res. 25, 1249-1256. https://doi.org/10.1097/00000374200109000-00002.

Ródenas-González, F., Blanco-Gandía, M.C., Miñarro, J., Rodríguez-Arias, M., 2020. Behavioral and neuroimmune characterization of resilience to social stress: rewarding effects of cocaine. Adicciones 1348. https://doi.org/10.20882/adicciones. 1348. Advance online publication.

Rodríguez-Arias, M., Montagud-Romero, S., Guardia-Carrión, A.M., Ferrer-Pérez, C. Pérez-Villalba, A., Marco, E., López-Gallardo, M., Viveros, M.P., Miñarro, J., 2018. Social stress during adolescence activates long-term microglia inflammation insult in reward processing nuclei. PLoS One 13, e0206421. https://doi.org/10.1371/journal. pone.0206421.

Rodríguez-Arias, M., Navarrete, F., Blanco-Gandía, M.C., Arenas, M.C., Bartoll-Andrés, A., Aguilar, M.A., Rubio, G., Miñarro, J., Manzanares, J., 2016. Social defeat in adolescent mice increases vulnerability to alcohol consumption. Addict. Biol. 21, 87-97. https://doi.org/10.1111/adb.12184.

Rodríguez-Arias, M., Montagud-Romero, S., Rubio-Araiz, A., Aguilar, M.A., Martín-García, E., Cabrera, R., Maldonado, R., Porcu, F., Colado, M.I., Miñarro, J., 2017. Effects of repeated social defeat on adolescent mice on cocaine-induced CPP and self-administration in adulthood: integrity of the blood-brain barrier. Addict. Biol. 22, 129-141. https://doi.org/10.1111/adb.12301.

Rodríguez-Arias, M., Miñarro, J., Aguilar, M.A., Pinazo, J., Simón, V.M., 1998. Effects of risperidone and SCH 23390 on isolation-induced aggression in male mice. Eur. Neuropsychopharmacol. 8, 95-103. https://doi.org/10.1016/S0924-977X(97) 00051-5.

Rossetti, A.C., Papp, M., Gruca, P., Paladini, M.S., Racagni, G., Riva, M.A., Molteni, R., 2016. Stress-induced anhedonia is associated with the activation of the inflammatory system in the rat brain: restorative effect of pharmacological intervention. Pharmacol. Res. 103, 1-12. https://doi.org/10.1016/j.phrs.2015.10.022.

Ruisoto, P., Contador, I., 2019. The role of stress in drug addiction. An integrative review. Physiol. Behav. 202, 62-68. https://doi.org/10.1016/j.physbeh.2019.01.022.

Salam, J.N., Fox, J.H., Detroy, E.M., Guignon, M.H., Wohl, D.F., Falls, W.A., 2009. 
M.D. Reguilón, et al.

Drug and Alcohol Dependence 212 (2020) 108004

Voluntary exercise in C57 mice is anxiolytic across several measures of anxiety. Behav. Brain Res. 197, 31. https://doi.org/10.1016/j.bbr.2008.07.036.

Samson, H.H., 1986. Initiation of ethanol reinforcement using a sucrose-substitution procedure in food-and water-sated rats. Alcohol. Clin. Exp. Res. 10, 436-442. https:// doi.org/10.1111/j.1530-0277.1986.tb05120.x.

Samson, H.H., Czachowski, C.L., 2003. Behavioral measures of alcohol self-administration and intake control: rodent models. Int. Rev. Neurobiol. 54, 107-143. https://doi.org/ 10.1016/s0074-7742(03)54004-1.

Sawicki, C.M., McKim, D.B., Wohleb, E.S., Jarrett, B.L., Reader, B.F., Norden, D.M., Godbout, J.P., Sheridan, J.F., 2015. Social defeat promotes a reactive endothelium in a brain region-dependent manner with increased expression of key adhesion molecules, selectins and chemokines associated with the recruitment of myeloid cells to the brain. Neuroscience 302, 151-164. https://doi.org/10.1016/j.neuroscience. 2014.10.004.

Somkuwar, S.S., Fannon, M.J., Ghofranian, A., Quigley, J.A., Dutta, R.R., Galinato, M.H., Mandyam, C.D., 2016. Wheel running reduces ethanol seeking by increasing neuronal activation and reducing oligodendroglial/neuroinflammatory factors in the medial prefrontal cortex. Brain Behav. Immun. 58, 357-368. https://doi.org/10. 1016/j.bbi.2016.08.006.

Spielman, L.J., Estaki, M., Ghosh, S., Gibson, D.L., Klegeris, A., 2017. The effects of voluntary wheel running on neuroinflammatory status: role of monocyte chemoattractant protein-1. Mol. Cell. Neurosci. 79, 93-102. https://doi.org/10.1016/j.mcn. 2016.12.009.

Stankiewicz, A.M., Goscik, J., Majewska, A., Swiergiel, A.H., Juszczak, G.R., 2015. The effect of acute and chronic social stress on the hippocampal transcriptome in mice. PLoS One 10, e0142195. https://doi.org/10.1371/journal.pone.0142195.

Svensson, M., Rosvall, P., Boza-Serrano, A., Andersson, E., Lexell, J., Deierborg, T., 2016. Forced treadmill exercise can induce stress and increase neuronal damage in a mouse model of global cerebral ischemia. Neurobiol. Stress 5, 8-18. https://doi.org/10. 1016/j.ynstr.2016.09.002.

Tanner, M.K., Fallon, I.P., Baratta, M.V., Greenwood, B.N., 2019. Voluntary exercise enables stress resistance in females. Behav. Brain Res. 369, 111923. https://doi.org/ 10.1016/j.bbr.2019.111923.

Van Erp, A.M.M., Miczek, K.A., 2001. Persistent suppression of ethanol self-administration by brief social stress in rats and increased startle response as index of withdrawal. Physiol. Behav. 73, 301-311. https://doi.org/10.1016/S0031-9384(01) 00458-9.

Watanasriyakul, W.T., Wardwell, J., McNeal, N., Schultz, R., Woodbury, M., Dagner, A., Cox, M., Grippo, A.J., 2018. Voluntary physical exercise protects against behavioral and endocrine reactivity to social and environmental stressors in the prairie vole. Soc. Neurosci. 13, 602-615. https://doi.org/10.1080/17470919.2017.1365761.

Watanasriyakul, W.T., Normann, M.C., Akinbo, O.I., Colburn, W., Dagner, A., Grippo, A.J., 2019. Protective neuroendocrine effects of environmental enrichment and voluntary exercise against social isolation: evidence for mediation by limbic structures. Stress 22, 603-618. https://doi.org/10.1080/10253890.2019.1617691.

Wei, F., Moore, D.C., Wei, L., Li, Y., Zhang, G., Wei, X., Lee, J.K., Chen, Q., 2012. Attenuation of osteoarthritis via blockade of the SDF-1/CXCR4 signaling pathway. Arthritis Res. Ther. 14, R177. https://doi.org/10.1186/ar3930.

Wohleb, E.S., Hanke, M.L., Corona, A.W., Powell, N.D., Stiner, L.M., Bailey, M.T., Nelson, R.J., Godbout, J.P., Sheridan, J.F., 2011. B-adrenergic receptor antagonism prevents anxiety-like behavior and microglial reactivity induced by repeated social defeat. J. Neurosci. 31, 6277-6288. https://doi.org/10.1523/JNEUROSCI.0450-11.2011.

Wohleb, E.S., Fenn, A.M., Pacenta, A.M., Powell, N.D., Sheridan, J.F., Godbout, J.P., 2012. Peripheral innate immune challenge exaggerated microglia activation, increased the number of inflammatory CNS macrophages, and prolonged social withdrawal in socially defeated mice. Psychoneuroendocrinology 37, 1491-1505. https:// doi.org/10.1016/j.psyneuen.2012.02.003.

Wohleb, E.S., Powell, N.D., Godbout, J.P., Sheridan, J.F., 2013. Stress-induced recruitment of bone marrow-derived monocytes to the brain promotes anxiety-like behavior. J. Neurosci. 33, 13820-13833. https://doi.org/10.1523/JNEUROSCI.1671-13. 2013.

Wohleb, E.S., McKim, D.B., Sheridan, J.F., Godbout, J.P., 2014. Monocyte trafficking to the brain with stress and inflammation: a novel axis of immune-to-brain communication that influences mood and behavior. Front. Neurosci. 8, 447. https://doi.org/ 10.3389/fnins.2014.00447.

Wood, S.K., Wood, C.S., Lombard, C.M., Lee, C.S., Zhang, X., Finnell, J.E., Valentino, R.J., 2015. Inflammatory factors mediate vulnerability to a social stress-induced depressive-like phenotype in passive coping rats. Biol. Psychiatry 78, 38-48. https://doi. org/10.1016/j.biopsych.2014.10.026.

Zhang, J., He, Z., Wang, L., Yuan, W., Li, L., Hou, W., Yang, Y., Gou, Q.Q., Zhang, X.N., Cai, W.Q., An, S.C., Tai, F., 2019. Voluntary wheel running reverses deficits in social behavior induced by chronic social defeat stress in mice: involvement of the dopamine system. Front. Neurosci. 13, 256. https://doi.org/10.3389/fnins.2019.00256.

Zheng, H., Liu, Y., Li, W., Yang, B., Chen, D., Wang, X., Jiang, Z., Wang, H., Wang, Z., Cornelisson, G., Halberg, F., 2006. Beneficial effects of exercise and its molecular mechanisms on depression in rats. Behav. Brain Res. 168, 47-55. https://doi.org/10. 1016/j.bbr.2005.10.007.

11 